\title{
Capital Allocation in the Insurance Sector*
}

\section{Dóra Balog}

Capital allocation plays a key role in the enterprise risk management system of insurance undertakings: when applied during performance measurement, it creates a link between risk and business. In addition to performance measurement, capital allocation may also have a role in pricing decisions and in the preparation of strategic business decisions. With the entering into force of the Solvency II regulation the consistent application of capital allocation has become a regulatory expectation in the insurance sector which lands relevance to our topic. The available literature is extremely rich; however, the applicable methods have been designed based on theoretic axioms rather than the needs of the practitioners, so the gap between theoretic research and real-life application is significant. Our objective is to translate the rather abstract formulation of the problem of capital allocation, customary in the literature, to the practical questions arising during implementation by insurance companies; thereby, providing some guidance for choosing the theoretically applicable methods. In this study, we will review the issues arising in connection with the implementation of capital allocation: what needs to be allocated for what specific purposes and how such allocation should take place.

Journal of Economic Literature (JEL) codes: G22, G32, C71

Keywords: capital allocation, insurance, Solvency II Directive

\section{Introduction}

As insurance events are stochastic by their nature, even if the most advanced statistical methods are applied, the collected premiums and reserves may not cover the claims against the insurer. In such a scenario, the solvency capital guarantees that the insurer can continue meeting its obligations. In other words: the solvency capital is intended to cover the losses incurred in case of the unexpected

* The views expressed in this paper are those of the author(s) and do not necessarily reflect the offical view of the Magyar Nemzeti Bank.

Dóra Balog is a PhD student of the General and Quantitative Economics Doctoral School of Corvinus University of Budapest. She conducts her research at the Department of Finance. E-mail: dora.balog1@gmail.com.

I want to thank my thesis supervisor Péter Csóka for the professional guidance and advice for writing this paper. I also want to thank David Ruhm and Russ Bingham who provided invaluable help by sharing their experiences. I also owe gratitude to Miklós Pintér and the participants of the KDI Conference organized by Corvinus University of Budapest: dr. József Banyár, Péter Boros, Judit Hevér, Eszter Kovács and Róbert Szini for their input.

The Hungarian manuscript was received on 6 October 2016.

DOI: http://doi.org/10.25201/FER.16.3.7497 
unfavourable development of events. Although the solvency capital provides protection for the losses suffered by any business line, it is important to know for a number of reasons to what extent the various business lines contribute to the insurer's capital requirements. Keeping capital is costly, and the allocation of such cost is a rather relevant factor for evaluating the performance of business lines and various product portfolios, for product pricing and for certain strategic decisions (e.g. acquisitions, mergers, starting a new or terminating an existing business line). Insurance companies typically allocate their capital to business lines, subsidiaries, products or product groups, but allocation to various geographic regions or possibly even to distribution channels. This problem is not new but the entry into force of the Solvency $\mathrm{II}^{1}$ Directive as of 1 January 2016 makes it especially relevant for insurance undertakings. The first pillar of the directive introduces new rules for capital and capital requirement calculations (causing a change in the volume of capital to be allocated). As part of the own risk and solvency assessment process (hereinafter ORSA) prescribed under the second pillar, the capital allocation process itself becomes subject to regulatory supervision (through the requirements pertaining to the integrated enterprise risk management system). Quoting the study of MaumeDeschamps et al. (2016): "The ORSA (Own Risk and Solvency Assessment) approach of the second pillar makes capital allocation an important exercise for all insurers $[\ldots]]^{\prime \prime}$. Developing integrated enterprise risk management (ERM) systems ${ }^{2}$ for insurers is a task of key relevance not only because of the Solvency II requirements. As McKinsey points out (Bongiovanni et al. 2016), insurers having a more advanced enterprise risk management system performed significantly better compared to their peers during the crisis (2008 and 2009). Having recognized that the insurers themselves started to deploy significant resources for developing their ERM systems. Capital allocation is an important component of these ERM systems, since through performance measurement the insurer compares the return (characterising the profitability of the business) realised by its different business lines (subsidiaries, portfolios) to the capital requirement allocated for the given unit (being a relevant risk indicator).

Literature on capital allocation is extremely wide-ranging; however, it mainly focuses on methodology issues of mostly theoretic nature: authors typically apply game theory (e.g. Denault 2001; Csóka et al. 2009, Csóka and Pintér 2016), option pricing (e.g. Myers - Read 2001; Sherris 2006; Kim - Hardy 2007) or other statistical approaches (e.g. Kalkberener 2005; Homburg - Scherpereel 2008; Buch-Dorfleitner 2008). By contrast, little reference is made to issues of practical application, as Kim and Hardy (2007:23) writes, "capital allocation methodology has mainly been developed based on a list of axioms rather than on motivation and a little has been researched on how the given capital allocation can be used in light of its

\footnotetext{
${ }^{1}$ Directive 2009/138/EC of the European Parliament and of the Council.

${ }^{2}$ See for instance McKinsey\&Company (2014).
} 
motivations." The objective of our study is to reduce this gap: we want to give an overview of the topic from a pragmatic viewpoint, focusing on the insurance sector.

This study is composed of the following parts. In the second chapter, we provide a formal description of capital allocation, and in the following sections we will use the notations introduced here for discussing the various issues at hand. In the third chapter, we present the possible applications, that is, why capital allocation is important and what insurance companies use it for. In the fourth chapter, we define the possible capital concepts and we examine what exactly we distribute during capital allocation. In the fifth chapter, we discuss how the allocation should be performed: we list the various applicable methods and the properties we can expect from them. It is always up to the entity using the method to set the priorities in any given capital allocation situation among the many possible expectations, but the summary "map" we prepared as the aggregation of the criteria referred to in the literature (often under different names) may be helpful. Moreover, we define which methods/method types are the most suitable for the various applications. Chapter six concludes.

\section{Description of capital allocation, notations}

Interpreted for insurers, the problem of capital allocation can be formulated as follows: an insurer is made up of a limited number of subunits (let's call them business lines, but they could also be portfolios or subsidiaries etc.). Let $N=\{1,2, \ldots, n\}$ denote the set of the lines of businesses. The returns of the various business lines are described by random variables on the $(\Omega, \mathrm{M}, \mathrm{P})$ probability field, where $\Omega$ is the finite set of possible outcomes, M denotes the possible subsets of $\Omega$, while $P$ is a probability distribution on $(\Omega, \mathrm{M})$. Let the set of probability variables interpreted on $(\Omega, \mathrm{M}, \mathrm{P})$ be $X$. Let $X_{i} \in X$ designate the net income (loss) realised by business line $i$, so $\sum_{i=1}^{n} X_{i}=X_{N}$ is the insurer's net income. We measure risk by the $\rho: X \rightarrow \mathbb{R}$ risk measure. The risk measure assigns a real number to the portfolio of a business line (or to a portfolio of a set of several business lines), representing the guarantee for absorbing unexpected losses (we usually call this capital). The application of coherent measures of risk is broadly accepted in the literature ${ }^{3}$ (see for example Csóka 2003). Let's denote the capital allocation situation as follows: $X_{N}^{\rho}=\left\{N,\left\{X_{i}\right\}_{i \in N}, \rho\right\}$, and their sets as $R C A S_{N}$ ("risk capital allocation situation"), while the capital allocation method itself is the $\varphi: R C A S_{N} \rightarrow \mathbb{R}^{N}$ function, which assigns one vector to every capital allocation situation, containing the capital allocated to each business line (a specific numeric example can be found in the article of Balog et al. 2010, among others) The purpose of our study is to translate the above defined methodological and theoretic problem to the issues arising

\footnotetext{
${ }^{3}$ Coherent risk measures satisfy the conditions of monotonicity, subadditivity, positive homogeneity, and translation invariance.
} 
during the day to day activity of insurance undertakings. In the next chapter, we will discuss the various aspects of the allocation problem with the help of the above described notations.

\section{Applications of capital allocation}

There are many different application areas of capital allocation. It is used by banks, insurers, fund managers, and also in a number of other nonfinancial areas in the form of cost allocation. In our study, we only focus on the insurance sector; however, even within this sector, we can encounter diverse applications, as presented below.

\subsection{Performance measurement}

Performance measurement is undoubtedly the most important and the most widespread application of capital allocation. In this case the performance (return) achieved by the business line (or, for example, by the subsidiary) is measured in comparison to the capital tied up by them. The most frequently used indicator for evaluating risk-adjusted performance is RORAC (Return On Risk Adjusted Capital), which based on Tasche (2008) can be indicated as follows relating to the entire insurer:

$$
\operatorname{RORAC}(X)=\frac{E\left(X_{N}\right)}{\rho\left(X_{N}\right)}=\frac{\sum_{i=1}^{n} E\left(X_{i}\right)}{\rho\left(X_{N}\right)}
$$

where, using the notations from Chapter 2 , the $X_{1}, \ldots X_{n}$ random variables are the profits (losses) of each business line, $\sum_{i=1}^{n} X_{i}=X_{N}$ is the profit/loss of the entire insurer; and $\rho\left(X_{N}\right)$ is the insurer's capital requirement measured by risk measure $\rho$. The RORAC indicators of the various business lines are thus:

$$
\operatorname{RORAC}\left(X_{i} \mid X\right)=\frac{E\left(X_{i}\right)}{\varphi_{i}\left(X_{N}^{\rho}\right)}
$$

where $\varphi_{i}\left(X_{N}^{\rho}\right)$ stands for the capital allocated to business line $i$. Although the main concern of our study is the denominator of the above expression, we must note here that it is extremely important to proceed carefully when defining the contents of the numerator. The first important question is whether we apply the RORAC indicator ex ante or ex post. The ex-ante application is more typical in case of strategic decisions (e.g. to analyse the impact of a major transaction), while the ex post approach is generally used in connection with performance measurement when the numerator contains the actually realised return. When calculating the RORAC, insurers generally take into account their net income after taxes and loss write-offs (Cummins 2000).

The treatment of the return realised on investment funds derived from the different products also deserves attention when defining the profit. Namely, due to the 
nature of insurance business (collection of premiums, then the payment of claims at a future date), insurers generate a substantial amount of funds to invest; therefore, the proper recognition of the arising risk is rather important and also that we take into account the realised profit in a manner consistent with such investments. We can manage risks in two ways: we either distribute them among the various business lines in proportion to total assets (that is, e.g., we manage the risk of the investment funds derived from the premiums of life insurances together with the risks of life insurances), or we regard the investment division as a separate business line in the course of allocation. We need to consider the purpose of capital allocation when deciding which one of the two approaches should be used. In the course of performance measurement, it is logical to treat investments separately, because underwriting insurance risks and taking investment decisions are, in most cases, completely separated; according to the general practice of insurers, these two activities are handled separately. At the same time, it is also true that the funds to invest are generated by selling insurance products; thus, the insurer implicitly assumes that the business lines invest such funds into risk free investments in a maturity structure adjusted to the expected future cash flow (this would happen if no separate business line existed at the insurer) in performance measurement. And the profit realised on investments are recognized in such a way that only the profit (loss) realised on top of the risk-free return is "accounted" for the investment business line. Bingham (2014), for example, presents a performance measurement and capital allocation model operating on a similar principle at an American insurer.

Pricing is an exception to the above practice. Namely, if we recognize the profit on investments under insurance products, this is equivalent to the reduction of the product's price in the course of pricing and insurers often act this way on very competitive markets.

\subsection{Strategic decisions}

The application of capital allocation methods in the course of strategic decision making assumes an advanced enterprise risk management practice. Capital allocation techniques may also be applied in the course of evaluating planned acquisitions and mergers and decisions concerning the launching of new business lines or the development or termination of existing ones.

Assessing the change in capital requirements is a key component of the preliminary assessment of any transaction. With the help of capital allocation, we can estimate not only the change in capital requirement on the level of the entire insurance undertaking, but also how the contribution of each existing business line to the total risk of the insurer changes. This is a very relevant information because even substantial changes may occur in the measured profitability of the business lines. 
Risk adjusted profit (see in the previous subchapter) is also an important input in the course of strategic planning, since it is the basis for deciding which business line's development increases the value of the company the most and which one should be shed (see for example Venter 2004). When capital allocation is intended to support strategic decisions, the applied methodology is very much similar to the one used for performance measurement, however, such measurement takes place using expected profitability and risk indicators instead of historic ones.

\subsection{Pricing}

The third important application area for insurers is pricing. According to Venter (2009), insurance professionals accept the traditional (CAPM) pricing model to a lesser extent than representatives of other financial institutions, due to the fat tail loss distribution approach primarily characterising the life insurance business line, which cannot be properly modelled using the first and second momentum. Consequently, insurers have the need for pricing models that are based on capital allocation methods. The survey on economic capital prepared by Mueller et al. (2004) under the auspices of the Society of Actuaries ${ }^{4}$ also shows that a large part of insurance undertakings use the allocated economic capital for product pricing. As a general approach, the price (the premium) of an insurance product results from the following factors (Werner-Modlin 2016:5):

\section{Premium $=$ Receivables from contracts + Costs related to payments + Contracting expenses + Profit}

In the above expression, in the optimal case, the profit should cover the expected return on capital: the higher the capital need of a product is, the more profit is expected from it. The capital need of each product can again be defined using capital allocation methods. Although in principle it would be possible to allocate capital directly for products, but in practice this is way too complicated, and the necessary data are not available either on product level. For this reason, when actually defining the capital cost of a given product, the capital allocated to a given business line is typically distributed to the products with the help of some linear approach. Therefore, the profit factor featured in the price of a product can be expressed as $(H R-r) \cdot \varphi_{i}\left(X_{N}^{\rho}\right)$, where $H R$ is the expected return on capital ("hurdle rate" $^{\prime \prime}, r$ is the risk-free return (return realised on the assets ensuring the capital), and $\varphi_{i}\left(X_{N}^{\rho}\right)$ represents the capital allocated to the given product.

However, there is no consensus whether the cost of capital should be built into the product price in such a way. Namely, in another approach, capital cannot play a role in pricing as pricing must be based only on the distribution of the insured risk. Based on this argumentation, thanks to the stringent capital regulations for

\footnotetext{
${ }^{4}$ Society of Actuaries.
} 
insurance undertakings, having excess capital over the required level no longer has additional value, as insured parties will not pay more for the same insurance policy based on the solvency of the party providing the insurance. (However, this, does not mean that capital allocation methods are not needed, as even they are not used for pricing, defining the allocated capital in the course of evaluating the performance of business lines is nonetheless needed: the most relevant information for management is the return realised on the invested equity.)

\section{Concept of capital in the literature}

As a first step to capital allocation, we need to clarify what exactly we want to allocate, that is, what we mean by the insurer's capital. Although this question may seem trivial, we encounter a great deal of capital concepts either in the literature or when analysing the balance sheets of insurers (regulatory capital requirement, economic capital requirement, various accounting categories). Most studies discussing capital allocation treat the definition of capital with extreme simplification (which is, of course, understandable as methods can be applied for many problems, each of which have a different definition of capital or the risk to be allocated; just as for banks and insurers the terminology and the contents are also different).

As the first step (as proposed by Farr et al. 2008), we must differentiate the concepts of capital requirement (a theoretic capital requirement quantified by some risk measurement method) and available capital. Available capital is an accounting category which, with some level of simplification, can be simply read from the insurer's balance sheet as the difference of assets and liabilities. Albrecht (2006) uses the also suggestive "physical capital" designation. Required capital should be broken down to at least two additional groups, as also proposed by the "Specialty Guide on Economic Capital" by the Society of Actuaries (Mueller et al. 2004): to regulatory capital requirement and economic capital requirement ${ }^{5}$. In case of solvent financial enterprises, the level of available capital exceeds both the value of the regulatory capital requirement and the economic capital requirement, while there is no generally valid relation between the levels of the latter two.

\subsection{Regulatory capital requirement - Solvency II}

By regulatory capital requirement we mean the compulsory minimum capital requirement prescribed by the regulator - in the European Economic Area this means the capital requirement as per Solvency II. Below we will shortly present the requirements of the directive introduced in January 2016, which are of major relevance for the players of the European insurance sector.

\footnotetext{
${ }^{5}$ In practice, the regulatory capital requirement and the economic capital requirement is typically simply referred to as regulatory or economic capital, but to avoid misunderstanding, we will not use the abbreviated form.
} 
Similarly to Basel II (and since then Basel III) pertaining to banks, Solvency II is built on three pillars. The first pillar covers quantitative requirements: the methodology for the required capital calculation and the evaluation rules of certain balance sheet items. For calculating their capital requirements, insurers may decide to apply either the standard method or a partially or fully internal model, the application of the latter two being subject to preliminary supervisory authorization. Whether computed with an internal model or with the standard method, the capital requirement as per Solvency II (SCR - Solvency Capital Requirement) corresponds to a value at risk (VaR) calculated with a 99.5 per cent significance level and a 12-month time horizon (that is, the level of loss which is expected to be exceeded only once every 200 years). Capital requirement calculation in a VaR sense is a significant progress compared to the much less risk sensitive, ratio-based capital calculation practice under Solvency I. Another relevant difference is that the new directive prescribes evaluation based on market prices instead of the previous, book value based evaluation (as per the evaluation standards applied in the given country). The difference between the old and new approaches are demonstrated by the following figure:

\section{Figure 1}

The regulatory capital requirement as per Solvency I and Solvency II Directives ${ }^{6}$

\section{Solvency I}

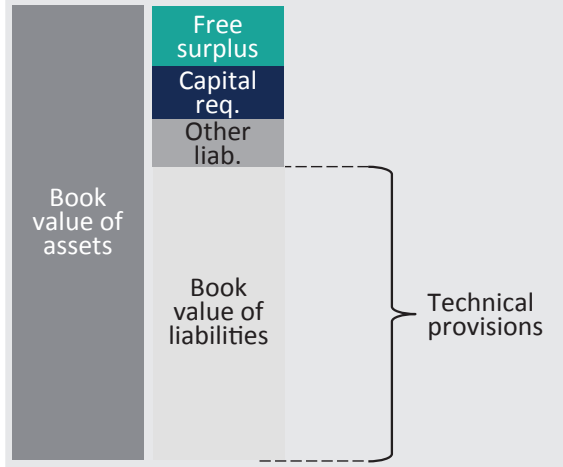

\section{Solvency II}

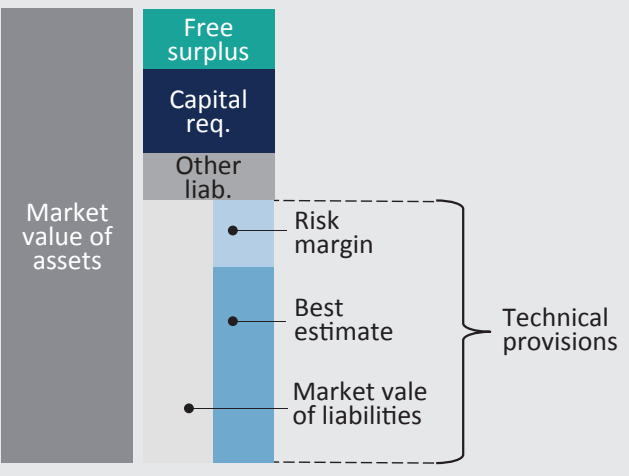

The second pillar supplements the quantitative requirements of pillar one by qualitative requirements. Besides the outline of the supervisory review procedure, the second pillar contains the requirements pertaining to the company's internal governance and risk management system and its internal capital calculation. Pursuant to the requirements pertaining to the risk management system, risk

\footnotetext{
${ }^{6}$ According to Article 77 of the Directive "The risk margin shall be such as to ensure that the value of the technical provisions is equivalent to the amount that insurance and reinsurance undertakings would be expected to require in order to take over and meet the insurance and reinsurance obligations".
} 
management function must be an integral part of the company ${ }^{7}$. Having a well embedded enterprise risk management (ERM) system into the companies' daily operation was already part of best practices in the insurance sector, but it only became a regulatory requirement under Solvency II. Among the requirements pertaining to risk management, the directive also expects the existence of a function and processes (policies and procedures) for the identification, measurement and management of the relevant risks as well as the related reporting procedure.

The ORSA process is an important component of the second pillar, which is the equivalent of the banks' ICAAP ${ }^{8}$ for the insurance sector. The ORSA process covers the internal (economic) capital requirement calculation (which although it is controlled by the regulator, it does not have an actual capital generation requirement on theoretic level), hence economic capital requirement calculation also becomes subject to supervisory control under Solvency II. In addition to capital modelling, the second pillar also places much emphasis on the related organizational framework and processes: ORSA also ensures the existence of risk-management processes integrated into business decisions. ${ }^{9}$ Capital allocation becomes a key factor at this point, as it is one of the most important tools of the internal capital requirement calculation applied in the course of business and strategic decisions (for example, it links the business line's return with its risk, i.e. the capital allocated to it through performance measurement). For the sake of accuracy, let us note here that the directive mentions the capital allocation process explicitly ${ }^{10}$ only in respect of the companies using the partial or full internal model under the first pillar, but it follows logically that the existence of such capital allocation process is required in other cases as well (that is, when applying the standard method).

The third pillar of the Directive contains the reporting and disclosure obligations.

\subsection{Economic capital requirement}

Economic capital requirement means the capital requirement calculated based on the company's internal risk assessment. The objective of the economic capital requirement calculation is to assess and quantify as accurately as possible the insurer's risks. Modelling the economic capital requirement is part of the insurance company's internal risk assessment process and the company uses its result in its enterprise management system.

\footnotetext{
${ }^{7}$ According to Article 44 of the Directive "That risk-management system shall be effective and well integrated into the organisational structure and in the decision-making processes of the insurance or reinsurance undertaking."

8 Internal Capital Adequacy Assessment Process.

${ }^{9}$ According to Article 45 (4) of the Directive "The own-risk and solvency assessment shall be an integral part of the business strategy and shall be taken into account on an ongoing basis in the strategic decisions of the undertaking."

${ }^{10}$ Article 120.
} 
Sandström (2011:68) provides the following definition: "economic capital [requirement], is defined as the company's own amount of capital needed to meet future obligations arising from the existing business with a high degree of certainty over a defined time horizon and to maintain its external credit rating".

According to Mueller et al. (2004) although economic capital requirement can be defined in many different ways, common in all of these definitions is that it expresses the volume of capital necessary to cover the losses suffered by the insurer over a given period of time in case of an unfavourable evolution of events, with a predefined risk tolerance threshold (confidence level).

For us this capital concept is the most relevant of all, as this is the one resulting from the measurement of the insurer's (or any other entity's, portfolio's) riskiness; i.e., in practice it is the economic capital requirement that we quantify using a selected risk measure.

Comparing the concepts of economic and regulatory capital requirement, we can see that internal capital requirement calculated under the second pillar of the Directive can also be regarded as economic capital requirement. Previously economic and regulatory capital requirements (calculated under the first pillar) could have been substantially different due to the standardised and less risk sensitive nature of the regulatory approach; whereas today such difference has been substantially reduced (or even disappeared if the insurer uses its own internal model under Pillar 1) due to the more risk sensitive approach of Pillar 1. This is clearly demonstrated by the fact that the Directive defines capital requirement as per the standard method as a risk indicator equivalent to the 99.5 per cent VaR.

\subsection{Comparing capital concepts}

In order to apply the methods proposed in the literature, first we have to match the capital concepts used in the literature and in practice. Part of the studies discussing capital allocation from a theoretic perspective typically view capital allocation as the formal problem defined in Chapter 2, i.e. it interprets the capital as a risk $(\rho(X))$ quantified using some risk measure. Tasche (2008), Dhaene et al. (2012), Assa (2016), or Balog et al. (2017), among others follow this approach. This corresponds to the concept of required capital, as this is the amount of capital that must (should) be available based on the assessment of the firm's risks. It is obvious already at this point that the applied terminology is far from being standard, namely, capital defined in such a way is typically referred to in the literature (e.g. Tasche 2008) as economic capital. This is because previously only the economic capital requirement complied with the $\rho(X)$ expression in practice, reflecting the actual measurable risks of the portfolio concerned. However, as the result of substantial development of the regulation, today regulatory capital requirement is also defined in this approach, at least for the purposes of Solvency II. 
Studies working with option pricing apply a different approach (Myers - Read 2001; Sherris 2006; Kim - Hardy 2007), which considers capital as the difference between the value of assets and the present value of expected future claims based, as presented by the following schematic balance sheet.

\section{Figure 2}

The insurer's schematic balance sheet
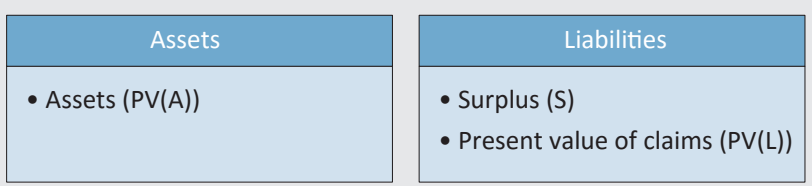

Using the notion "surplus" is common in this approach. The value of surplus is defined based on the accounting equation: $S=P V(A)-P V(L)$, where $P V(A)$ represents the present value of assets and $P V(L)$ denotes the present value of expected future claims. However, it is important to keep in mind that on the left side assets are shown at market value, that is $P V(A)$ already takes into account the probability of the insurer's bankruptcy, but $P V(L)$ does not calculate with such event. Namely, because of its limited liability, the insurer indeed has a put option referred to by the literature as default option ${ }^{11}$ (D). If the value of the insurer's liabilities exceeds the value of its assets at the end of the considered period $(L>A)$ it only has to pay $A$, so the value of the option is $D=P V(\max (0 ; L-A))$. We obtain the equity value $(E)$ in the model if we take into account the value of the default option also in the evaluation of liabilities, that is

$$
E=P V(A)-(P V(L)-D)=S+D
$$

Thus, the above-mentioned surplus (S) is an input variable for calculating the equity (E). ${ }^{12}$

It is very important to note that the above interpretation of surplus is not the same as the surplus capital defined by the Solvency II Directive (see Figure 1). Looking back at Figure 1 the market value of liabilities, $P V(L)-D$ in the Myers and Read (2001) approach corresponds to the technical provision (best estimate plus risk margin) in the figure. While equity value (E) is the sum of the SCR and the surplus capital shown in the figure. The concern with the Myers and Read (2001) approach is that in this interpretation capital is merely an accounting category derived from the accounting equation, which has little to do in itself with the company's risk profile.

\footnotetext{
${ }^{11}$ Use of the term "solvency exchange option" is also common.

${ }^{12}$ Butsic (1994) does not distinguish at all the surplus capital used by Myers and Read (2001) and the insurer's equity.
} 


\subsection{What should be allocated?}

This is the only question concerning capital allocation to which straightforward answer can be given: it is always recommended to allocate the economic capital requirement. As also noted by Vrieze and Brehm (2003) in their analysis of the practical implementation possibilities of Myers and Read's model (2001): economic capital requirement characterises the actual risk profile of the given institution; therefore, it is advisable to examine the allocation on this entity mutatis mutandis - consistently with those authors who define the capital to be allocated as $\rho(X)$.

In the course of performance measurement insurers used to base their calculations on regulatory capital requirement, but the use of the economic capital requirement is increasingly spreading (Mueller et al. 2004). This is useful not only because the economic capital requirement gives a more accurate picture of the actual risks taken by companies than the regulatory capital requirement ${ }^{13}$ but also because in the case of insurers present in several countries, the difference of regulatory capital requirements country by country may be an issue. Focusing on performance measurement, Albrecht ${ }^{14}$ (2006) provides detailed guidance on the capital types proposed to be applied and the adjustments to be done. For the sake of a more accurate risk assessment and also in view of the possible deviation of the regulatory capital requirements, it is advisable to use the economic and not the regulatory capital requirement for both pricing and individual performance measurement purposes.

\section{Selection of the allocation method}

The most important question in relation to capital allocation is probably the selection of the adequate allocation method. Several methods defined in different conceptual frameworks, having different properties can be found in the literature and it might be seriously challenging for practitioners to select the adequate method. This exercise is made even more difficult by the fact that authors often refer to the same characteristic under different names. To facilitate the practitioners' selection, we have collected the mathematical properties that can be expected from the available allocation methods (see Annex 1) and have summarised how these attributes - referred to by the different names of the various studies - can be matched (Annex 2).

Although a large number of possible methods exist for allocating risk capital, there is no general best practice solution. This is partly attributable to the impossibility

\footnotetext{
${ }^{13}$ Except if the two coincide.

${ }^{14}$ Albrecht (2006) refers to the regulatory capital requirement as external risk-based capital and the capital requirement calculated based on an internal model as virtual risk-based capital; he suggests the application of a modified version of the risk-based capital requirement in the course of performance measurement, i.e., the risk adjusted capital.
} 
of satisfying all the properties listed in Annex 1 at the same time. Csóka and Pintér (2016) prove that if coherent risk measures are applied, it is impossible to allocate capital in a way that it is strongly monotonous ${ }^{15}$, core compatible and satisfies equal treatment property, i.e., we must give up at least one of these three naturally occurring requirements. The same theorem also means that there is no method that fulfils the properties full domain, incentive compatibility and core compatibility (see Balog et al. 2017). This means that users have to choose from the various required properties and as such, from the different allocation methods based on the specific capital allocation situation. However, it also should be taken into account that the decision is a fairly complicated process in practice, as numerous players having different motivation can take part in it. For example, if we want to allocate the insurer's capital to lines of business, then the heads of the various business lines, the head of risk management and the company's management will have different motivations.

In order to facilitate the method selection, below we first group the applicable methods, then we suggest methods (method types) for the different applications based on some practically relevant considerations.

\subsection{Types of applicable methods}

\section{Proportionate allocations}

The methods that can be listed in this group distribute total risk $\left(\rho_{N}\left(X_{N}\right)\right)$ among the subunits proportionally: $\varphi_{i}\left(X_{N}^{\rho}\right)=\alpha \rho\left(X_{i}\right)$ in such a way that $\sum_{i=1}^{N} \varphi_{i}\left(X_{N}^{\rho}\right)=\rho\left(X_{N}\right)$. The big advantage of these methods is that their application is simple, yet their mathematical properties are less favourable. We must mention two methods among proportionate distributions. The activity-based method (Hamlen et al. 1977) distributes risk in proportion to the risk taken by the various units $\left(\rho\left(X_{i}\right)\right)$, which may seem an obvious solution, but its major shortcoming is that it fails to take into account the diversification effects among the various units (i.e. how much the given unit contributes to the risks of the overall organization). The so-called Beta or covariance method (see for example Dhaene et al. 2012) also belongs to proportionate distributions: its calculation is relatively simple, but it already takes into account diversification effects. The detailed analysis of both of these methods can be found in the study of Balog et al. (2017).

\section{Incremental allocations}

Incremental allocations, in line with their appellation, distribute risk among the various subunits account taken of the incremental risk caused by them. We can distinguish two types within these methods: "last-in" type methods (Venter 2009), which interpret increment on the entire portfolio $\left(\rho\left(X_{N}\right)-\rho\left(X_{N \backslash\{i\}}\right)\right)$, and the Shapley method which uses the average contribution of the given unit as reference.

${ }^{15}$ The explanation of the various properties is included in Annex 1. 
The "last-in" methods distribute risk based on the incremental risk of a given unit calculated on the entire portfolio $\left(\rho\left(X_{N}\right)-\rho\left(X_{N \backslash\{i\}}\right)\right)$. The incremental method (Jorion 2007), the cost gap method (Tijs - Driessen 1986), and the method proposed by Merton and Perold (1993) belong to this allocation type.

The Shapley method (Shapley, 1953) widely known from game theory offers a more sophisticated approach, also distributing risk based on the incremental risk caused by the given unit, evaluating it not only based on the portfolio of the entire insurer without the given unit $(N \backslash\{i\})$ ) but also in comparison with every possible $S \subseteq N \backslash\{i\}$ subset, taking the average of these. No wonder the Shapley method is so widespread: it has numerous favourable mathematical properties (see for instance Csóka and Pintér 2016).

\section{Marginal risk contribution}

The marginal risk contribution type methods include the often discussed Euler method (see for instance Tasche 2008), which allocates risk with the partial derivation of the risk measure, as well as the allocation based on directional derivatives (see Balog et al. 2017). If defined, the Euler method can be an optimal solution for pricing; and according to Tasche (2008) it may be an ideal choice for performance measurement as well since it is reconcilable with RORAC calculation. The also popular Myers-Read method (Myers and Read 2001) can also be grouped year, which, similarly to the Merton-Perold method, distributes the insurer's equity to the various lines of business account taken of the value of the bankruptcy option, applying the Euler method.

\subsection{Selection of the most suitable allocation method}

As we mentioned, there is no general best practice of capital allocation, method selection always should depend on the actual situation. To select the applied method, Albrecht (2006) formulates some practically relevant criteria as opposed to the exact requirements presented in Annex 1 (although he also considers full allocation as a basic condition). According to the study, it is important Is the allocation's consistency with the enterprise risk measurement; the properties of the risk measure used by the company; how dependency structure of the losses of various segments are taken into account; how the given method can be implemented in practice; and that the selected allocation method has the properties corresponding to the purpose of application. Ruhm and Wolf (2015) also add as a key factor that the applied allocation method should be acceptable for every stakeholder of the organization; that it should be stable in time and should not be allocate negative capital to any of the subunits.

For the purposes of practical application, we focused on individual rationality from among the mathematical properties listed in Annex 1, which expresses the requirement that the capital allocated to each unit should not exceed the 
individual risks of the given unit. Although "individual risk" is not necessarily a relevant basis for comparison in respect of a line of business or product portfolio, as individual business lines typically could not operate as independent units, this requirement is still a key fairness criterion and thus greatly aids the acceptance of the method by the concerned decision-makers. In addition, the transparency and the relative simplicity of the allocation mechanism are also key criteria in practice. The experiment conducted by Homburg and Scherpereel (2008) using real economic actors underpinned the primary role of the above criteria in the course of practical application. The authors found that due to the limited rationality of real economic players, the perceived fairness of the distribution is more influenced by transparency, simplicity and the fulfilment of individual rationality by the allocation mechanism than the satisfaction of the most frequently analysed core compatibility. The efficiency of the method is also considered a key aspect, that is, that the method should allocate the entire risk among the various lines of business. Thus, in line with Kalkbrener (2005), Albrecht (2006) and many other authors, our table includes only the methods meeting this criterion, so we are not indicating it specifically among the advantages of each method.

When it comes to the various applications, to support strategic decisions (planned acquisitions, mergers, assessment of starting a new line of business, or decision on the termination of an existing line of business), the incremental methods, especially the "last-in" types are the most suitable, as in such cases we can indeed assume that the entire portfolio is fixed, and we take the decision based on the relationship of the given line of business to such condition. This is also the argumentation used by Merton and Perold (1993:29) stating that "the marginal cost of capital must be taken into account for marginal decisions ${ }^{16 ",}$, and also by Buch et al. (2011) according to whom the selected methodology must also be aligned to the structure and nature of the subunits: in the case of few, heterogeneous subunits (such as decisions on termination of existing or launching of new business lines and the performance measurement of business lines) incremental allocation methods are more suitable. The Shapley method may also be an optimal solution for performance measurement: although its calculation is more complicated, it results in a stable and fair allocation, compared to the "last-in" methods.

For product pricing differential based methods are the most suitable, as subunits are more or less homogeneous and their portfolios contain a large number of contracts. For this reason, we believe that the Euler method is more suitable for pricing, although, according to Tasche (2008), it is also ideal for performance measurement. Myers and Read (2001) reached a similar conclusion. They demonstrate that their proposed allocation method is suitable to be used in pricing since the capital allocated does not sensitively react to the adding of new business lines; while for

\footnotetext{
${ }^{16}$ In their interpretation, this refers to the exiting from a given business line or launching a new one.
} 
the same reasons, it is less suitable for making decisions on new business lines and the termination of existing ones.

If the purpose of capital allocation is only to meet external (regulatory or parent company) requirements, then it may also be justified to use the simplest proportionate methods (of the two, the activity-based method can be implemented the easiest).

The following summary table gives an overview of the methods best suited to the different applications. For each method (method type) we show the advantages and disadvantages most relevant in the course of practical application. The study of Balog et al. (2017) may also be of additional help for selecting the adequate method where the authors analyse in detail the mathematical properties of each method.

\begin{tabular}{|c|c|c|c|c|}
\hline \multicolumn{5}{|l|}{ Table 1} \\
\hline $\begin{array}{l}\text { Objective of } \\
\text { allocation }\end{array}$ & $\begin{array}{l}\text { Recommended } \\
\text { method type }\end{array}$ & $\begin{array}{l}\text { Recommended } \\
\text { method }\end{array}$ & Advantages & Disadvantages \\
\hline $\begin{array}{l}\text { Performance } \\
\text { measurement }\end{array}$ & $\begin{array}{l}\text { Incremental risk } \\
\text { based }\end{array}$ & Shapley method & $\begin{array}{l}\text { - IR } \\
\text { - Clear } \\
\text { interpretation } \\
\text { - Favourable other } \\
\text { mathematical } \\
\text { properties }\end{array}$ & $\begin{array}{l}\text { - Its calculation is } \\
\text { fairly complicated }\end{array}$ \\
\hline \multirow[t]{2}{*}{$\begin{array}{l}\text { Performance } \\
\text { measurement \& } \\
\text { Strategic decisions }\end{array}$} & \multirow[t]{2}{*}{$\begin{array}{l}\text { Incremental risk } \\
\text { based (last entrant) }\end{array}$} & $\begin{array}{l}\text { Incremental } \\
\text { method }\end{array}$ & $\begin{array}{l}\text { - Simple } \\
\text { application } \\
\text { - Clear } \\
\text { interpretation }\end{array}$ & $\begin{array}{l}\text { - Non-IR } \\
\text { - The increment } \\
\text { may be negative } \\
\text { resulting in } \\
\text { counter intuitive } \\
\text { distribution }\end{array}$ \\
\hline & & Cost gap & $\begin{array}{l}\text { - IR } \\
\text { - Clear } \\
\text { interpretation }\end{array}$ & $\begin{array}{l}\text { - Its calculation is } \\
\text { fairly complicated }\end{array}$ \\
\hline Pricing & $\begin{array}{l}\text { Marginal } \\
\text { contribution to risk }\end{array}$ & $\begin{array}{l}\text { Euler method / } \\
\text { Myers-Read } \\
\text { method }\end{array}$ & $\begin{array}{l}\text { - IR in practice } \\
\text { - Its calculation } \\
\text { a simple using } \\
\text { the RMK } \\
\text { algorithm }{ }^{17}\end{array}$ & $\begin{array}{l}\text { Unstable result } \\
\text { under certain } \\
\text { circumstances }^{18}\end{array}$ \\
\hline $\begin{array}{l}\text { In case of external } \\
\text { expectation }\end{array}$ & Proportionate & $\begin{array}{l}\text { Activity-based / } \\
\text { Beta method }\end{array}$ & $\begin{array}{l}\text { - Simple } \\
\text { application } \\
\text { - Clear } \\
\text { interpretation }\end{array}$ & $\begin{array}{l}\text { - Non-IR } \\
\text { - The least } \\
\text { favourable } \\
\text { mathematical } \\
\text { properties }\end{array}$ \\
\hline
\end{tabular}

${ }^{17}$ RMK: Ruhm-Mango Kreps algorithms, see for instance Ruhm and Mango (2003).

${ }^{18}$ The essence of this method is that the risks allocated to each portfolio are defined based on their realization in the world situations determining the risk of the entire portfolio. (For instance: if maximum loss is applied, how much is the loss of each subunit when the loss of the total portfolio is at its maximum.) If we use few data points when defining the risk of the large coalition, the result may become incidental. 


\section{Conclusion}

Although the literature on capital allocation is very rich and a large number of different methods have already been designed, the majority of the studies covering this topic derive methods from desired (or considered to be desirable) mathematical properties and not based on the users' motivation. The purpose of our study is to reduce the gap theory and practice by providing some guidance for the method selection and implementation, furthermore even for the formulation of the capital allocation problem itself.

The first step of capital allocation is to define the type of capital to be allocated. It is important to distinguish regulatory capital requirement, economic capital requirement and available capital. We found that it is always the economic capital requirement that should be allocated as it is the one that actually reflects the risk profile of the company.

Since there is no generally applicable best practice for the capital allocation problem, the selection of the method should always be aligned to the purpose of application. We identified the three main application areas of capital allocation at insurance companies and recommend which method types should be applied in the various cases as well as the advantages and disadvantages of the methods.

Incremental methods are the most suitable for performance measurement and for supporting strategic decisions. These methods distribute total risk among the subunits account taken of the incremental risk caused by them. For the best choice relating to strategic decisions are the "last-in" methods (which consider how the risk of the total portfolio changes when adding/taking away a given unit), while the Shapley method, well known from game theory, results in a more stable allocation with more favourable properties in the course of performance measurement. The third important area of application is pricing, although the experts are arguing whether there is any need for using allocation methods for pricing. If pricing takes place with the help of capital allocation, then the most suitable for this purpose are the marginal risk contribution methods: the Euler method and a special version of it, the Myers-Read method. To meet an external requirement, when the insurer does not actually use the allocation results, it is best to apply the simple proportionate distributions.

To further facilitate the method selection, we collected the possible properties of capital allocation methods mentioned in the literature (Annex 1 ) and in a summary table we also listed the different names used by the different authors to refer to these properties (Annex 2). 


\section{References}

Albrecht, P. (2006): Risk based capital allocation. In: Encyclopaedia of Actuarial Science. Wiley, Chichester.

De Angelis, P. - Granito, I. (2015): Capital allocation and risk appetite under Solvency II framework. Occasional Papers. https://arxiv.org/abs/1511.02934.

Assa, H. - Morales, M. - Firouzi, H.O. (2016): On the Capital Allocation Problem for a New Coherent Risk Measure in Collective Risk Theory. Risks 4(3): 30. https://doi.org/10.3390/ risks4030030.

Balog, D. - Csóka, P. - Pintér, M. (2010): Tökeallokáció nem likvid porfoliók esetén. (Capital allocation in case of non-liquid profiles) Hitelintézeti Szemle (Financial and Economic Review) 49: 1-9.

Balog, D. - Bátyi, T. - Csóka, P. - Pintér, M. (2011): Tőkeallokációs módszerek és tulajdonságaik a gyakorlatban. (Capital allocation methods and their properties in practice) Közgazdasági Szemle, 58(7-8): 619-632.

Balog, D. - Bátyi, T. - Csóka, P. - Pintér, M. (2017): Properties and comparison of risk capital allocation methods. European Journal of Operational Research 259(2): 614-625. https:// doi.org/10.1016/j.ejor.2016.10.052.

Bingham, R. (2014): Using the Risk Coverage Ratio to Integrate Risk and Return. Contingencies 26(6): 54-59.

Bongiovanni, C. - Pancaldi, L. - Stegernann, U. - Taglioni, G. (2016): Transforming enterprise risk management for value in the insurance industry. McKinsey \& Company Report. http:// www.mckinsey.com/business-functions/risk/our-insights/transforming-enterprise-riskmanagement-for-value-in-the-insurance-industry.

Buch, A. - Dorfleitner, G. (2008): Coherent Risk Measures, Coherent Capital Allocation and the Gradient Allocation Principle. Insurance: Mathematics and Economics 42(1): 235-242. https://doi.org/10.1016/j.insmatheco.2007.02.006.

Buch, A. - Dorfleitner, G. - Wimmer, M. (2011): Risk capital allocation for RORAC optimization. Journal of Banking and Finance 35: 3001-3009. https://doi.org/10.1016/j. jbankfin.2011.04.001.

Butsic, R.P. (1994): Solvency Measurement for Property-Liability Risk-Based Capital Applications. Journal of Risk and Insurance, 61: 656-690. https://doi.org/10.2307/253643.

Csóka, P. (2003): Koherens kockázatmérés és tőkeallokáció. (Coherent risk measurement and capital allocation) Közgazdasági Szemle, 50(10): 855-880. 
Csóka, P. - Herings, P.JJ. - Kóczy, Á. L. (2009): Stable allocations of risk. Games and Economic Behaviour 67(1): 266-276. https://doi.org/10.1016/j.geb.2008.11.001.

Csóka, P. - Herings, P.JJ. (2014): Risk Allocation under Liquidity Constraints. Journal of Banking and Finance 49: 1-9. https://doi.org/10.1016/j.jbankfin.2014.08.017.

Csóka, P. - Pintér, M. (2016): On the Impossibility of Fair Risk Allocation. The B.E. Journal of Theoretical Economics 16(1):143-158.

Cummins, J.D. (2000): Allocation of Capital in the Insurance Industry. Risk Management and Insurance Review 3: 7-28. https://doi.org/10.1111/j.1540-6296.2000.tb00013.x.

Denault, M. (2001): Coherent Allocation of Risk Capital. Journal of Risk 4(1): 1-34. https:// doi.org/10.21314/JOR.2001.053.

Dhaene, J. - Tsanakas, A. - Valdez, E.A. - Vanduffel, A. (2012): Optimal Capital Allocation Principles. Journal of Risk and Insurance 79(1): 1-28. https://doi.org/10.1111/j.15396975.2011.01408.x.

European Commission (2009): Directive 2009/138/EC of the European parliament and of the council of 25 November 2009 on the taking-up and pursuit of the business of insurance and reinsurance (Solvency II). Official Journal of the European Union, p. L335.

Farr, I. - Mueller, H. - Scanlon, M. - Stronkhorst, S. (2008): Economic Capital for Life Insurance Companies. Society of Actuaries Report. https://www.soa.org/files/pdf/research-ec-report. pdf.

Hamlen, S.S. - Hamlen, W.A. - Tschirhart, J.T. (1977): The Use of Core Theory in Evaluating Joint Cost Allocation Games. The Accounting Review 52: 616-627.

Homburg, C. - Scherpereel, P. (2008): How Should the Cost of Joint Risk Capital be Allocated for Performance Measurement? European Journal of Operational Research 187(1): 208217. https://doi.org/10.1016/j.ejor.2007.03.020.

Hougaard, J.L. - Smilgins, A. (2016): Risk Capital Allocation with Autonomous Subunits: The Lorenz Set. Insurance: Mathematics and Economics 67: 151-157. https://doi. org/10.1016/j.insmatheco.2015.12.002.

Jorion, P. (2007): Value at Risk: The New Benchmark for Managing Financial Risk. McGraw - Hill.

Kalkbrener, M. (2005): An Axiomatic Approach to Capital Allocation. Mathematical Finance 15(3): 425-437. https://doi.org/10.1111/j.1467-9965.2005.00227.x. 
Kim, J.H.T. - Hardy, M.R. (2007): A Capital Allocation Based on a Solvency Exchange Option. Working Paper. http://citeseerx.ist.psu.edu/viewdoc/ download?doi=10.1.1.412.2088\&rep=rep1\&type=pdf.

Maume-Deschamps, V. - Rulliere, D. - Said, K. (2016): On a capital allocation by minimization of some risk indicators. European Actuarial Journal 6(1): 177-196. https://doi.org/10.1007/ s13385-016-0123-1.

McKinsey\&Company (2014) From Compliance to Value Creation: The Journey to Effective Enterprise Risk Management for Insurers. McKinsey Report. http://www.mckinsey. $\mathrm{com} / \sim /$ media/mckinsey/business\%20functions/risk/our\%20insights/transforming\%20 enterprise\%20risk\%20management\%20for\%20value\%20in\%20the\%20insurance\%20 industry/from-compliance-to-value-creation.ashx.

Merton, R.C. - Perold, A.F. (1993): Theory of Risk Capital in Financial Firms. Journal of Applied Corporate Finance 6: 16-32. https://doi.org/10.1111/j.1745-6622.1993.tb00231.x.

Mueller, H. (2004): Specialty Guide on Economic Capital. Society of Actuaries Report. https:// www.actuaries.org.uk/documents/specialty-guide-economic-capital.

Myers, S.C. - Read, J.A. (2001): Capital Allocation for Insurance Companies. Journal of Risk and Insurance 68: 545-580. https://doi.org/10.2307/2691539.

Ruhm, D. - Mango, D. (2003): A Risk Charge Calculation Based on Conditional Probability. 2003 Bowles Symposium, Georgia State University. https://www.casact.com/education/ specsem/sp2003/papers/ruhm-mango.doc.

Ruhm, D. - Wolf, R. (2015): RCM-3 and 4: Allocating Capital - A Hands-on Case Study. Lecture on the seminar of Casualty Actuary Society, 11 March 2015 https://cas.confex. com/cas/rpms15/webprogram/Handout/Paper4123/Wolf_\%20RPM2015\%20Seminar\%20 Session\%20_wolf_ruhm.pdf.

Sandström, A. (2011): Handbook of Solvency for Actuaries and Risk Managers: Theory and Practice. CRC Finance series. Chapman \& Hall/CRC, 2011.

Shapley, L.S. (1953): A value for n-person games. In: Kuhn HW, Tucker AW (eds) Contributions to the Theory of Games II, Annals of Mathematics Studies, vol 28, Princeton University Press, Princeton, pp. 307-317. https://doi.org/10.1515/9781400881970-018.

Sherris, M. (2006): Solvency, Capital Allocation, and Fair Rate of Return in Insurance. The Journal of Risk and Insurance 73(1): 71-96. https://doi.org/10.1111/j.13652966.2006.00166.x.

Tasche, D. (2008): Capital Allocation to Business Units and Sub-Portfolios: the Euler Principle. Occasional Paper. http://arxiv.org/PS_cache/arxiv/pdf/0708/0708.2542v3.pdf. 
Tijs, S.H. - Driessen, T.S.H. (1986): Game theory and cost allocation progress. Management Science 32(8): 1015-1028.

Venter, G.G. (2004): Capital Allocation Survey with Commentary. North American Actuarial Journal 8(2): 96-107. https://doi.org/10.1080/10920277.2004.10596139.

Venter, G.G. (2009): Next Steps for ERM: Valuation and Risk Pricing. Society of Actuaries Report. In Additional Research Papers Submitted to the 2009 ERM Call for Papers.

Vrieze, K.J. - Brehm, P.J. (2003): Review of "Capital Allocation for Insurance Companies" by Steward C. Myers and James R. Read Jr. Practical Considerations for Implementing the Myers-Read Model. The Casualty Actuarial Society Forum. Fall 2003 Edition: 479-492. http://www.casact.org/pubs/forum/03fforum/03fforum.pdf.

Werner, G. - Modlin, C. (2016): Basic ratemaking. Casualty Actuarial Society's publication. https://www.casact.org/library/studynotes/Werner_Modlin_Ratemaking.pdf. 